\title{
It is time to improve the quality of medical information distributed to students across social media
}

This article was published in the following Dove Press journal:

Advances in Medical Education and Practice

\author{
Benjamin E Zucker' \\ Christos Kontovounisios ${ }^{1,2}$ \\ 'Imperial College London, School of \\ Medicine, London, UK; ' ${ }^{2}$ Department \\ of Surgery and Cancer, Chelsea \\ and Westminster Hospital, Imperial \\ College London NHS Trust, \\ London, UK
}

\begin{abstract}
The ubiquitous nature of social media has meant that its effects on fields outside of social communication have begun to be felt. The generation undergoing medical education are of the generation referred to as "digital natives", and as such routinely incorporate social media into their education. Social media's incorporation into medical education includes its use as a platform to distribute information to the public ("distributive education") and as a platform to provide information to a specific audience ("push education"). These functions have proved beneficial in many regards, such as enabling constant access to the subject matter, other learners, and educators. However, the usefulness of using social media as part of medical education is limited by the vast quantities of poor quality information and the time required to find information of sufficient quality and relevance, a problem confounded by many student's preoccupation with "efficient" learning. In this Perspective, the authors discuss whether social media has proved useful as a tool for medical education. The current growth in the use of social media as a tool for medical education seems to be principally supported by students' desire for efficient learning rather than by the efficacy of social media as a resource for medical education. Therefore, improvements in the quality of information required to maximize the impact of social media as a tool for medical education are required. Suggested improvements include an increase in the amount of educational content distributed on social media produced by academic institutions, such as universities and journals.
\end{abstract}

Keywords: social media, medical education, push education, distributive education

\section{Perspective}

The central role that social media plays in the lives of many young people and students means that its utilization for medical education provides a unique opportunity to provide the efficient form of learning that so many students desire. However, it is not only the efficiency of social media-based education that makes it useful but also the increased degree of accessibility to information; the provision of information in innovative ways, including the use of multimedia presentations; and facilitating collaboration through group messaging. ${ }^{1,2}$ On the other hand, the potential benefit that social media may have is limited by the credibility of the information ${ }^{3}$ as well as the time required to find good-quality information.

This Perspective will, therefore, aim to consider to what degree the incorporation of social media into medical education helps students, and the improvements required to maximize its benefit. The functions of social media discussed are those that educators may have a key role in improving, specifically its function to distribute information to
Correspondence: Benjamin E Zucker Imperial College London, School of Medicine, South Kensington Campus, London, SW7 2AZ, UK

Tel +44 7881628692

Email benjaminzucker@googlemail.com 
a general audience (“distributive education"), and its ability to direct information at a specific audience ("push education").

\section{Distributive education}

Social media websites and applications are online environments or communities where users explore content primarily generated by fellow users. An advantage of this is that the content is likely to be relevant to the users as well as being easy to access. Although peer-review is by no means a perfect process, and is prone to bias, the lack of it in regulating information on social media means that the reliability of such information is uncertain. ${ }^{4}$ It is likely that students are aware of the possible shortcomings of user generated content. Despite this, the use of social media for the purposes of education continues to grow, with some reports suggesting up to $52 \%$ of health profession students use online media as their primary source of information. ${ }^{5}$ Therefore, consideration of both the factors that continue to drive student use of these platforms is warranted along with strategies to remedy its shortcomings.

Wikipedia, an open access source of user-generated information, has been suggested to be used by students for quickly "finding background information". ${ }^{6}$ However, a review of 40 English respiratory articles on Wikipedia suggested that many were brief or incomplete in key areas, challenging their suitability as a learning resource for medical students. ${ }^{7}$ Students awareness of the limitations of user-generated content indicates that Wikipedia offers something to students that renders the possibility of incomplete information worthwhile. As stated above, efficiency and ease of access are strong driving factors for the use of online media; however, the frequency with which Wikipedia is used might indicate that it offers something unique to the learning experience of students. Perhaps, the strict formatting of medically related articles on Wikipedia provides a consistent framework in which students can process information.

YouTube certainly has a unique ability to provide education in an innovative form, such as multimedia presentations. It is, therefore, unsurprising that students are attracted to the use of this platform as a learning resource, particularly when the information pertains to topics in which visual demonstration may aid the understanding of conceptually challenging topics. ${ }^{8}$ However, many videos are found to be wanting in educational value, due to poor image quality or due to the inclusion of serious errors in the content. A further problem is that the low percentage of good-quality videos may mean that students have to spend excess time finding educational resources of good quality, therefore detracting from the efficacy of social media-based learning. However, the content produced by academic journals and institutions constitutes a large proportion of the videos that are considered good quality. ${ }^{9}$ It is possible that the reliability of content produced by academic institutions and journals stems from the role they play in the peer-review process, indicating that the lack of this process in user-generated content may be limiting its suitability for students.

The lack of a peer-review system for online media published for the purposes of medical education has the dual effect of reducing the average quality of resources for medical education, compared to their traditional counterparts, while also to providing a smoke screen of sub-par resources that mask the resources that may be of use. Despite these obvious problems, the use of social media as a learning resource is growing, potentially signifying that students appreciate the ease of access of information and also perceive it as an "efficient" tool for learning. However, more can be done to increase the reliability, and suitability for students, of information on these platforms. As usergenerated content is incompatible with a peer-review system, a possible solution would be to increase the proportion of sources of online information provided by academic institutions and journals. This would serve both to render online media more useful to students, while also drawing positive attention to themselves as a source of reliable information resources for students.

\section{Push education}

Institutions such as universities have made use of "Push" technologies on social media for medical education with some success. "Push" technology involves signing up to a service, such as a WhatsApp group or a Twitter feed, and then receiving information through information transactions initiated by the publisher (or the educator) as opposed to the user. Students seem to enjoy the use of these tools, with viewing these tools favorably being positively correlated with frequency of use. ${ }^{10}$ It is likely the enablement of "onthe-go" learning that these tools provide drives students positive views toward it, with students specifically praising the high yield of information obtained from subscribing to an educational Twitter feed. Despite this, the use of the tool was not found to influence engagement on the clinical placement nor was it found to influence exam results. It is possible that more could have been made of the tool if, in addition to the push aspect, it was used as a platform for group discussion and collaborative education, thereby capitalizing not only 
with the educator's connectivity to the students but also with the students' connectivity with each other. Herein lies the potential benefit of social media applications with broad ranging capabilities, like Facebook. Students can follow pages or people which can frequently "push" educational content to learners while also incorporating discussion boards that facilitate collaborative education.

\section{Synthesis and future implications}

Seemingly, there is a disconnect between what students and educators think of as a useful resource for students. Despite the fact that a large proportion of the resources on platforms used for "distributive education" are found to be inadequate or inappropriate for students and the fact that the use of Push technologies to educate students may not help achieve better results, the use of social media for medical education is still growing substantially. It is likely that this is occurring for a number of reasons. It is possible that students value efficiency in learning sufficiently to be willing to risk accessing subpar resources. It is also possible that the current generation undergoing medical education's familiarity with social media and online resources means that they are simply more comfortable using these platforms than more traditional ones. Regardless, responsibility now falls on educators to improve the quality of the information distributed across social media to students. Furthermore, teaching students how to critically appraise social media sources will lead to a reduction in use of poor-quality sources perpetuating false or incomplete information. This would enable students to take greater responsibility for their own learning.

However, as discussed above, a significant change that must occur is the increased production of educational content for use on social media by academic institutions and journals, with the aim of building channels known by students for reputable content. The creation of online discussion boards to facilitate collaboration between learners could serve to improve the content's quality by providing corrections and feedback. In this way, user-generated content could undergo a form of user-generated peer review.

\section{Acknowledgments}

Benjamin E Zucker studied preclinical medicine at Jesus College Cambridge and is now studying clinical medicine at Imperial College London.

Christos Kontovounisios is a consultant colorectal surgeon at Chelsea and Westminster Hospital and an honorary Clinical Senior Lecturer in the Department of Surgery and Cancer at Imperial College London.

\section{Disclosure}

The authors report no conflicts of interest in this work.

\section{References}

1. Cheston CC, Flickinger TE, Chisolm MS. Social media use in medical education: a systematic review. Acad Med. 2013;88(6):893-901.

2. Batt-Rawden S, Flickinger T, Weiner J, Cheston C, Chisolm M. The role of social media in clinical excellence. Clin Teach. 2014;11(4):264-269.

3. Azer SA. Can "YouTube" help students in learning surface anatomy? Surg Radiol Anat. 2012;34(5):465-468.

4. Kleynhans AC, Oosthuizen AH, van Hoving DJ. Emergency medicine educational resource use in Cape Town: modern or traditional? Postgrad Med J. 2017;93(1099):250-255.

5. Usher K, Woods C, Casellac E, et al. Australian health professions student use of social media. Collegian. 2014;21(2):95-101.

6. Lim S. How and why do college students use Wikipedia? J Am Soc Inf Sci Technol. 2009;60(11):2189-2202.

7. Azer SA. Is Wikipedia a reliable learning resource for medical students? Evaluating respiratory topics. Adv Physiol Educ. 2015;39(1):5-14.

8. Azer SA, Aleshaiwi SM, Algrain HA, Alkhelaif RA. Nervous system examination on YouTube. BMC Med Educ. 2012;12:126.

9. Hickman SJ. An evaluation of educational neurological eye movement disorder videos posted on internet video sharing sites. J Neuroophthalmol. 2016 ;36(1):33-36.

10. Reames BN, Sheetz KH, Englesbe MJ, Waits SA. Evaluating the use of Twitter to enhance the educational experience of a medical school surgery clerkship. J Surg Educ. 2016;73(1):73-78. reviewed, open access journal that aims to present and publish research on Medical Education covering medical, dental, nursing and allied health care professional education. The journal covers undergraduate education, postgraduate training and continuing medical education

including emerging trends and innovative models linking education, research, and health care services. The manuscript management system is completely online and includes a very quick and fair peer-review system. Visit http://www.dovepress.com/testimonials.php to read real quotes from published authors. 